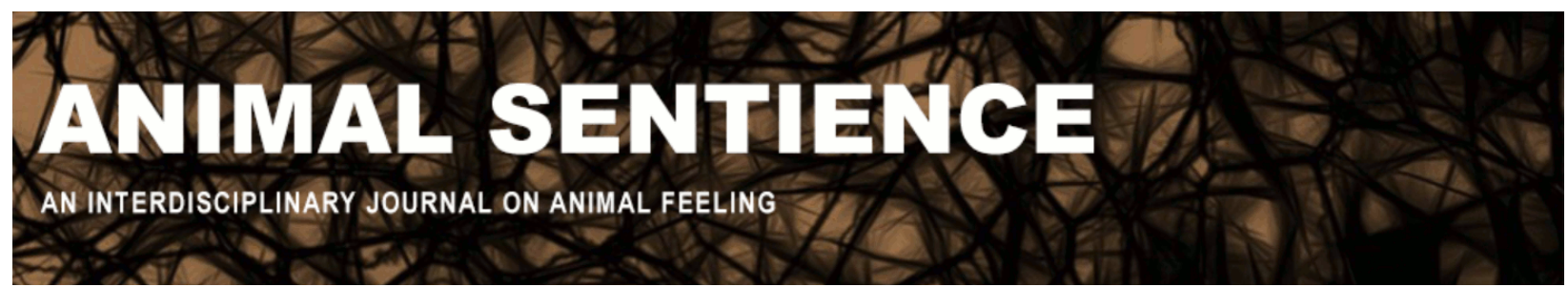

Ristau, Carolyn (2016) Evidence for animal grief?. Animal Sentience 4(8) DOI: $10.51291 / 2377-7478.1014$

Date of submission: 2015-05-20

Date of acceptance: 2015-12-13

(c) (i)




\title{
Evidence for animal grief?
}

Commentary on King on Animal Grief

\author{
Carolyn Ristau \\ Little Neck, New York
}

\begin{abstract}
The nature of evidence appropriate to the study of animal emotion (and cognition) is discussed in this review with reference to Barbara King's book. How Animals Grieve is beautifully written, but it intermixes examples meeting King's criteria for evidence of grief with other poignant but far less convincing examples. Yet, as noted earlier by Griffin (1958/1974), "Excessive caution can sometimes lead one as far astray as rash enthusiasm." King cites strong evidence from long-term scientific field studies, often involving known individuals; from videotapes; from convergent evidence in neurophysiological studies; and, notwithstanding possible emotional bias, from animals living closely with humans. She makes salient points about data from one-time occurrences and variability, distinguishing experience from expression, and cautioning about over-emphasis on statistics without adequate contextual description. She is persuasive, with both caveats and recognition of the need to be open to the likelihood of animal emotional experience. Such possibilities have a great impact on our treatment of animals, individually and as a society.
\end{abstract}

\begin{abstract}
Carolyn A. Ristau carolynaristau@aol.com is a cognitive ethologist concerned with justice for humans and animals. Her research includes field studies of cognition and communication in human infants and non-humans, in particular primates and plovers. Address: 251-25 Gaskell Road, Little Neck, New York 11362 https://barnard.edu/profiles/carolyn-ristau
\end{abstract}

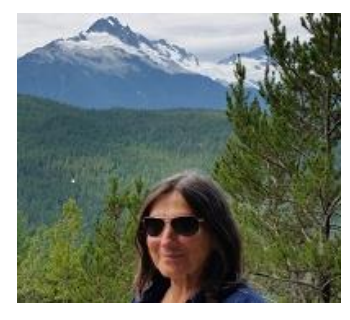

Barbara King's "Afterword" in How Animals Grieve (2013), was, for me as a scientist, the most satisfying section of the book. In it she distinguished between the examples of strong, moderate and weak evidence for animal grief that she had presented in her writing. For that I was indeed grateful.

That's not to say that her writing wasn't often poetic, which it was, nor that her anecdotes weren't often moving, which they were. But this is a scientific journal and I have been asked, not as one who appreciates poetry or one who occasionally tries creating her own, but as a scientist, to discuss a matter of some significance. Whether we as scientists believe there is adequate evidence that animals suffer grief and other negative (and positive) emotions can influence our legislation on the treatment of domestic animals, animals used for entertainment, and even wild animals, not to mention those we raise for our food. As individuals, what we believe about animal pain and cognition, about their sentience, about how similar to us they are, most likely influences our environmental concerns (e.g., whether and how tenaciously we preserve their habitat) as well as which foods we choose to eat. Our choices can have an impact on very 
important matters, notably the effect of a meat diet, particularly beef, on climate change. (Some factors are cows' production of methane, a more potent greenhouse gas than $\mathrm{CO}_{2}$, and the energy and resources needed to produce beef versus vegetables.)

Presumably by way of a summary of her beliefs, Barbara King ends the book with a quote from Meg Ahere, "I would prefer to start from the assumption that every animal feels emotions and loves others in its own way" (p. 166). That is most compassionate and it is wise to consider strongly that possibility, but one has misgivings from a scientific perspective. Let us examine first King's own criteria for evidence: "Grief can be said to occur when a survivor animal acts in ways that are visibly distressed or altered from the usual routine, in the aftermath of the death of a companion animal who had mattered emotionally to him or her" (p. 163). In fact, at various points, she adds the importance of videotaping such behaviors, presumably in ordinary situations for the animal and then after a companion's death. In some examples, she also cites neurophysiological correlates as another convergent line of evidence for the likely presence of an emotion.

But we are already in something of a quagmire: How do we know if an associate "mattered emotionally"? One indication may be their choosing to spend time together. Another one suggested by King is distress at separation, but what sorts of separation? Any separation? Animals do naturally spend time apart, depending on species, individuals, needs and the nature of the relationship. Are we meaning distress resulting from separation initiated and enforced by an outsider? Absence during usual times of association? Now we still have to worry about what we mean by "distressed," and it is important to decide how we can recognize and record it.

What of assuming animals do feel emotions and love? From an evolutionary point of view, aspects of that stance are most sensible. We have strong evidence that we and other nonhuman animals share certain characteristics of our skeleton, our bodily systems, our brain organization, and our cognitive capacities, so why not our emotional capacities? The question is which characteristics are shared, and what are the underlying mechanisms? The question is also which animals? I might guess that Ms. Ahere is thinking of companion animals, chimpanzees, food-producing animals, and maybe even some others. But what about insects, worms, sea slugs, reptiles, fish, and birds? These are deeply interesting and important questions, not to be quite so easily judged.

I also do not agree that the presence of an apparent emotion of grief implies that the organism has loved (e.g., p. 16, p. 38). I and many others have grieved when we heard about and saw photographs of the devastation caused by the earthquake in Nepal. My behavior did change from normal: I was saddened; I went on the internet and donated funds. I had recently visited Nepal, and although I very much enjoyed and appreciated the people, I cannot say that I loved them. Similarly, I would think, a non-human animal can see the dead or injured body of a stranger and feel some emotion, perhaps like grief. 
Notwithstanding my concerns, it is also the case that King has made many salient points in her discussion. She notes the importance of the rare or one-time event, as related by an experienced and knowledgeable observer (better with video, but that is understandably very difficult to achieve). Studies of non-human animals' possibly intelligent behavior can provide significant evidence in rare or one-time events, for intelligence can be revealed when an organism deals with situations never before encountered (i.e., not a product of learned, repeating behaviors).

King also notes that "peer reviewed scientific literature ... favor[s] statistical results and bare summaries over descriptive passages" (p. 83). Again she poses a reasonable concern, for field researchers recognize that the context of a behavior is critically important both in influencing the kind of behavior exhibited and in facilitating the most reasonable interpretation. Context requires description. However, statistics do matter too. If similar behaviors are observed over many occasions from members of a given species, rather than just once or a few times, we can be more confident that those behaviors are characteristic and not peculiar events where we missed some significant elements. It's a tough balance between statistics and the significance of variability.

King is wise to point out the variability in manifestations of grief between and within species and indeed, even within an individual; the same variability is true of humans. We, like other apes, can cause death or grieve over it; she notes Frans de Waal's (1982) reflection that we humans have an equal capacity for compassion and for cruelty (p. 86). It is not only a matter of differences in prior experience or in the nature of an individual's relationship with the absent companion; in fact, all brains are different.

In a related matter, King emphasizes the distinction between "experiencing" and "expressing" emotion. As observers we can mistake the absence of apparent expression for the absence of experience. Yet these sensibilities, unfortunately, make the positing of emotion, and especially a particular emotion, all the more difficult, though not impossible in all circumstances.

King does express an attitude that I find particularly problematic: "[T]to acknowledge that we humans think and feel differently from other living creatures need not amount to a manifesto of human superiority" (p. 156). To imply that all animals, non-human and human are equal, which, agreed, is not exactly what she is saying here, avoids some important and soul-searching issues and choices. We all are sorry that the chimpanzee, Ham, sent into space by the USA, presumably suffered during an unpredicted, accidental period of intense heat and that several monkeys before him died of accidents in the space program (pp. 77-78). Yet should a human have been the substitute? The same argument extends to drug testing, where we try to avoid tests with monkeys and apes and other animals who are very likely highly sentient, but there are hard choices to be made. Is the subject to be an indigent human who is paid to participate, a third- 
world human less protected by laws and enforcement, or a prisoner who has few choices? Do we instead choose not to create new drugs?

Even as we choose non-human animals, preferentially those we consider not sentient, instead of human animals, to undergo possible or likely suffering in projects we as a society deem important, we must be cognizant of a unique problem. There is, as Stevan Harnad has put it, a "profound asymmetry, when it comes to the other-minds problem" (personal communication). A false negative - wrongly inferring a lack of suffering when there is indeed suffering - has far more appalling consequences than the accuracy or inaccuracy of almost any other kind of scientific inference.

Despite all my concerns, I was persuaded by Barbara King's book, though I needed little such persuasion; my own research into the cognitive and communicative capacities and mental states of animals has made me most receptive (Ristau 1991, 2013). Others before me would have been receptive also. King referenced some, but strangely missing is Darwin's 1872 The Expression of the Emotions in Man and Animals and Donald R. Griffin's 1976 small, seminal book, The Question of Animal Awareness.

The evidence I found most convincing in King's book was indeed generally the kind described as "strong" in her "Afterword," namely, evidence that met her "stringent definition" for grief quoted earlier (p. 163). Long-term scientific research in the wild, often involving known individuals, as in some elephant populations, provided many examples. For instance, elephants acted distressed or unusually after the death of the matriarch; some caressed the bones of a dead animal. There was a suggestion that the latter might even be a generalized response to death. Might that be evolutionarily related to the behaviors of many of us after the Nepalese earthquake? Dolphin mothers can show great distress at the death of their infants. Some chimpanzee mothers will carry an infant's corpse even for weeks, as I myself have witnessed, though the full interpretation of that behavior could be complicated. But Jane Goodall's observations do indicate young chimpanzees' great distress at the loss of their mother. Some pair-bonded birds offer other strong evidence for grief. King also cites examples from animals living closely with humans, in homes, farms, sanctuaries, and zoos. However, when the observation is not recorded at the time, and when the human has an emotional tie with the animal, it is too easy to let such emotions color the reconstructed memory.

I was dissatisfied with the many anecdotes cited, lacking any of King's reasonable criteria for grief. She did note that they were not her own observations, but nevertheless she chose to include them, devoting considerable space to their description. As noted in a remark by Donald Griffin in 1958 concerning biologists' great reluctance at the time to consider the possibility of bats using sonar in echolocation (now well accepted), "Excessive caution can sometimes lead one as far astray as rash enthusiasm." 
We must also recognize that King wants to foster discussions and raise concerns among many people, not just scientists, in the hope that society will be more mindful of the animals who share the earth with us and whom we choose either to protect or not. That goal is laudable.

I cannot honestly stop there, however. What about the other humans among us, those who are poorer, with little power and few rights, who are abused, and sick, battling each other to death: are they not even more deserving of our research, our efforts and protection? Perhaps an awakened concern for animals can extend to our intelligence, compassion, and activism towards fellow humans as well.

\section{References}

Darwin, C. (1872). The Expression of the Emotions in Man and Animals. London, UK: Murray Press. (Reprinted 1965 by University of Chicago Press, Chicago, IL with Preface by Konrad Lorenz).

De Waal, F. B. M. (1982). Chimpanzee Politics. London, UK: Jonathan Cape.

Griffin, D. R. (1958). Listening in the Dark. New Haven, CT: Yale University Press. (Reprinted 1974 by Dover Press, New York, NY) as quoted in J. L. Gould, Griffin, Donald Redfield (1915-2003) in M. Bekoff (Ed.), Encyclopedia of Animal Behavior (Vol. 2). Westport, CT: Greenwood Press; 2004, 613-617, p. 613.

Griffin, D. R. (1976). The Question of Animal Awareness. New York, NY: Rockefeller University Press.

King, B. J. (2013) How animals grieve. Chicago, IL: University of Chicago Press.

Ristau, C. A. (1991). Aspects of the cognitive ethology of an injury-feigning bird, the piping plover. In C. A. Ristau (Ed.), Cognitive ethology: The minds of other animals (Essays in honor of Donald R. Griffin). Hillsdale, NJ: Lawrence Erlbaum Associates.

Ristau, C. A. (2013). Cognitive ethology: Advanced review. Wiley Interdisciplinary Reviews: Cognitive Science, 4(5), 493-509. doi: 10.1002/wcs.1239 